\title{
STRUCTURE AND MECHANICAL PROPERTIES OF ROLLED BARS FROM STEEL 42CrMo4
}

\author{
Dariusz KUC ${ }^{1}$, Iwona BEDNARCZYK ${ }^{1}$, Aleksandra KRAWCZYK², Włodzimierz PATEREK², \\ Karolina ZYGMUNT², Dariusz WOŹNIAK ${ }^{3}$, Eugeniusz HADASIK ${ }^{1}$ \\ ${ }^{1}$ Silesian University of Technology, Faculty of Materials Engineering and Metallurgy, Katowice, Poland, EU, \\ dariusz.kuc@polsl.pl \\ 2Huta Bankowa, Dąbrowa Górnicza, Poland, EU \\ ${ }^{3}$ Institute of Iron Industry, Gliwice, Poland, EU
}

https://doi.org/10.37904/metal.2019.827

\begin{abstract}
The paper presents the results of evaluation of the macro and microstructure as well as mechanical properties of rolled bars made from steel $42 \mathrm{CrMo} 4$ from continuously cast stock. The macrostructure was examined using Baumann's method and deep etching. Based on the examination of the macro and microstructure, it was shown that discontinuities and internal defects may occur during initial plastic processing of ingots by rolling. For high degree processing, a fine-grained structure is obtained, while for large bar diameters and low degree processing, there may be variations in the grain size in the cross-section. Mechanical properties determined from the static tensile test, impact test and hardness measurements indicate a greater influence of the sampling site than of the degree of plastic processing, which may results from both the quality of ingots and the rolling conditions.
\end{abstract}

Keywords: Structural steels, rolling of long products, plastic working

\section{INTRODUCTION}

The quality and properties of semi-finished products made by the rolling process depend on a number of factors, such as: the method of steel production and its post-furnace treatment, steel casting, plastic working and, possibly, heat treatment [1]. Despite using additional methods in the process of steel casting whose purpose is to improve the homogeneity of steel, ingots obtained for rolling still have internal defects, such as: axial porosity, central porosity, cracks, pinholes and blisters. Therefore, obtaining long products of good quality, i.e. of the desirable shape and dimensions, with the required strength and plastic properties and their uniform distribution across the cross-section, and without external and internal defects, requires a properly designed technological process, especially a properly selected degree of plastic processing [2]. Most often, the degree of plastic processing by rolling is equivalent to the elongation factor $\lambda$ and is calculated as the ratio of the initial cross-sectional area of the ingot (stock), $S_{o}$, to the cross-sectional area of the strip (product), $S_{i}$, after $i^{\text {th }}$ deformation. In this paper, the results are presented of the evaluation of the macro and microstructure as well as mechanical properties of rolled bars made from steel $42 \mathrm{CrMo} 4$ from continuously cast ingots.

\section{RESEARCH MATERIAL}

For macro and microstructure studies as well as for mechanical tests of the $42 \mathrm{CrMo} 4$ steel, two sections of $250 \mathrm{~mm}$ in length were sampled from round bars with diameters of $\phi 90, \phi 150, \phi 180$ and $\phi 200 \mathrm{~mm}$, and a 20 $\mathrm{mm}$ thick disc. The chemical composition of the steel verified with a spectrometer meets the requirements of the PN-EN 10083-2:2008 standard. The $\phi 90 \mathrm{~mm}$ and $\phi 150 \mathrm{~mm}$ bars were made from a $270 \times 320 \mathrm{~mm}$ ingot, which corresponds to processing degrees of 13.6 and 4.9 respectively; the $\phi 180 \mathrm{~mm}$ bars were made from a $390 \times 283 \mathrm{~mm}$ ingot, which corresponds to a processing degree of 4.3; and the $\phi 210 \mathrm{~mm}$ bars of a $\phi 410 \mathrm{~mm}$ ingot, corresponding to a processing degree of 4.2. Specimens were taken from one section to determine the mechanical properties (static tensile test, impact test) according to the scheme shown in Figure 1. Specimens for the microstructure examination were cut out from the head of a specimen for the tensile test. 
a)

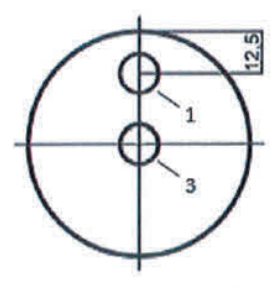

b)

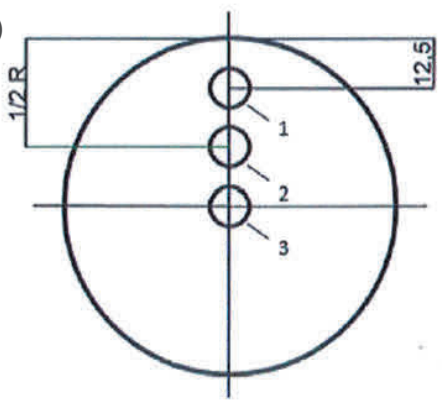

Figure 1 Diagram of sampling locations for tensile and impact tests: a) from the $\phi 90 \mathrm{~mm}$ bar, b) from the $\phi 150, \phi 180$ and $\phi 200 \mathrm{~mm}$ bars

A disc was sampled in order to perform a Baumann's test and deep etching, while hardness tests were performed on specimens prepared for the microstructure examination. The heads from impact tests, after analysis of their chemical composition, were used to determine the size of the primary austenite grain.

\section{MACROSCOPIC TESTS}

Macroscopic examination included a Baumann's test, performed in accordance with the PN-H-04514:1987 standard, and deep etching as per standard PN-H-04501:1957. The tests were carried out on transverse specimens and were aimed to detect internal defects of the obtained bars by rolling from continuously cast ingots. Examples of the macroscopic test results for the investigated steel 42CrMo4 are shown in Figure 2.

a)
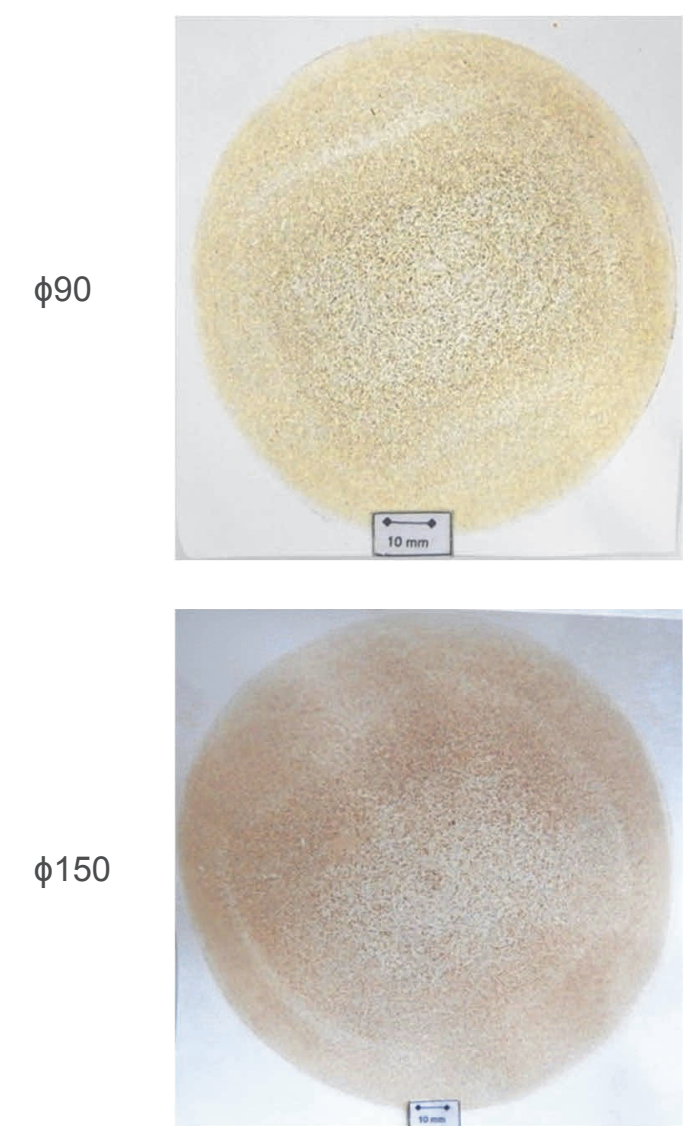

b)
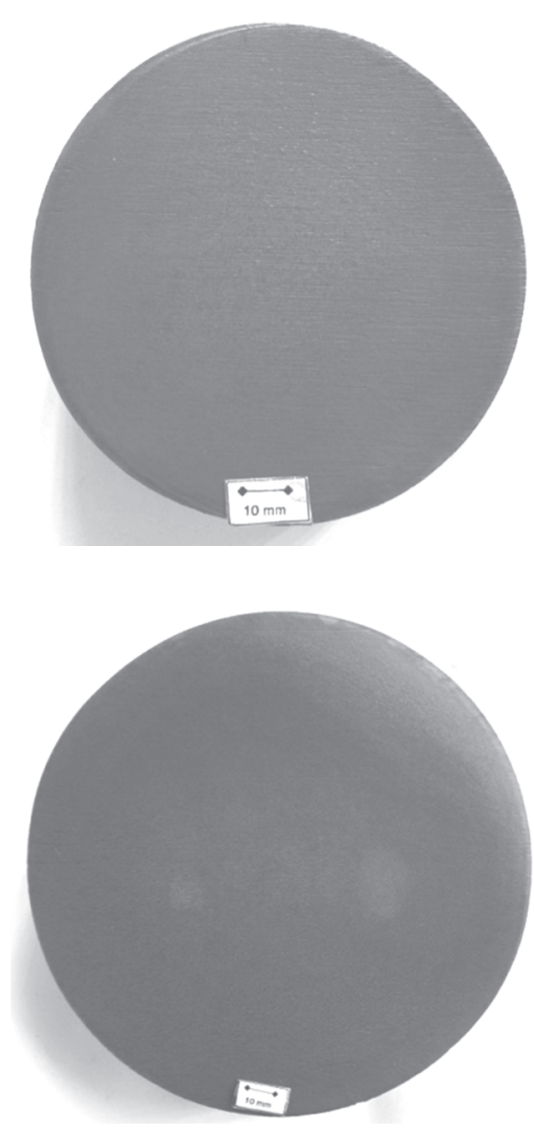

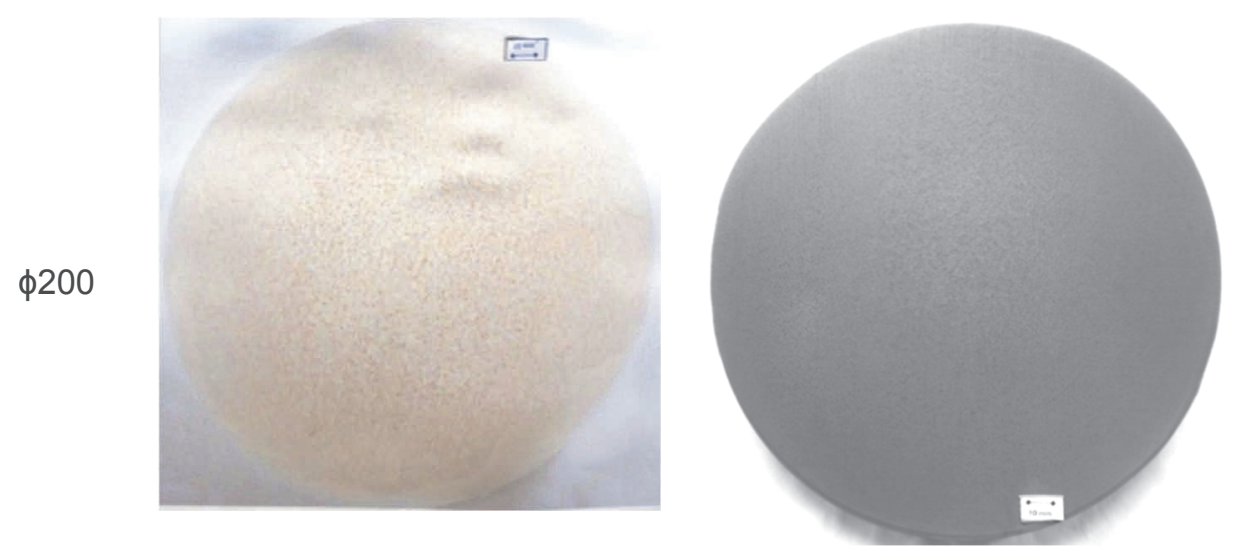

Figure 2 Macroscopic tests of steel 42CrMo4: a) Baumann's print

b) deep etching test

The results of Baumann's test show the presence of axial porosity within a $1 \mathrm{~mm}$ area for the $\phi 180 \mathrm{~mm}$ bar, and central porosity for the $\phi 90 \mathrm{~mm}, \phi 150 \mathrm{~mm}$ and $\phi 180 \mathrm{~mm}$ bars. A dendritic structure was found for the $\phi 180$ $\mathrm{mm}$ bar, while numerous pinholes occurred in the $\phi 90 \mathrm{~mm}$ bar only. For the $\phi 200 \mathrm{~mm}$ bar with the lowest processing degree, no internal defects were observed. The deep etching tests performed for steel $42 \mathrm{CrMo} 4$ practically did not reveal any internal defects. The only exception was the $\phi 90 \mathrm{~mm}$ bar, where central porosity was observed within an area of $70 \mathrm{~mm}$.

\section{MICROSCOPIC TESTS}

Microstructure tests were performed on transverse microsections using an Olympus GX51 microscope, at magnification of $50 x \div 1000 x$. Additionally, the analysis of the microstructure of the investigated steels was complemented by examination carried out on the Hitachi S-3400N scanning microscope. Examples of the microstructures of the bars of steel 42CrMo4 are presented in Figure 3. For the 42CrMo4 steel microsections, a pearlitic structure with the presence of a cementite lattice was found. In the case of the bars with smaller dimensions, i.e. $\phi 90$ and $\phi 150 \mathrm{~mm}$, the structure was finer and homogeneous, and for large bar diameters $\phi 180$ and $\phi 200 \mathrm{~mm}$, the refinement of the structure depended on the sampling location. A finer structure was characteristic of the specimens sampled at the surface of the bar, and the deeper into the bar axis, the larger the grain size.

Light microscope
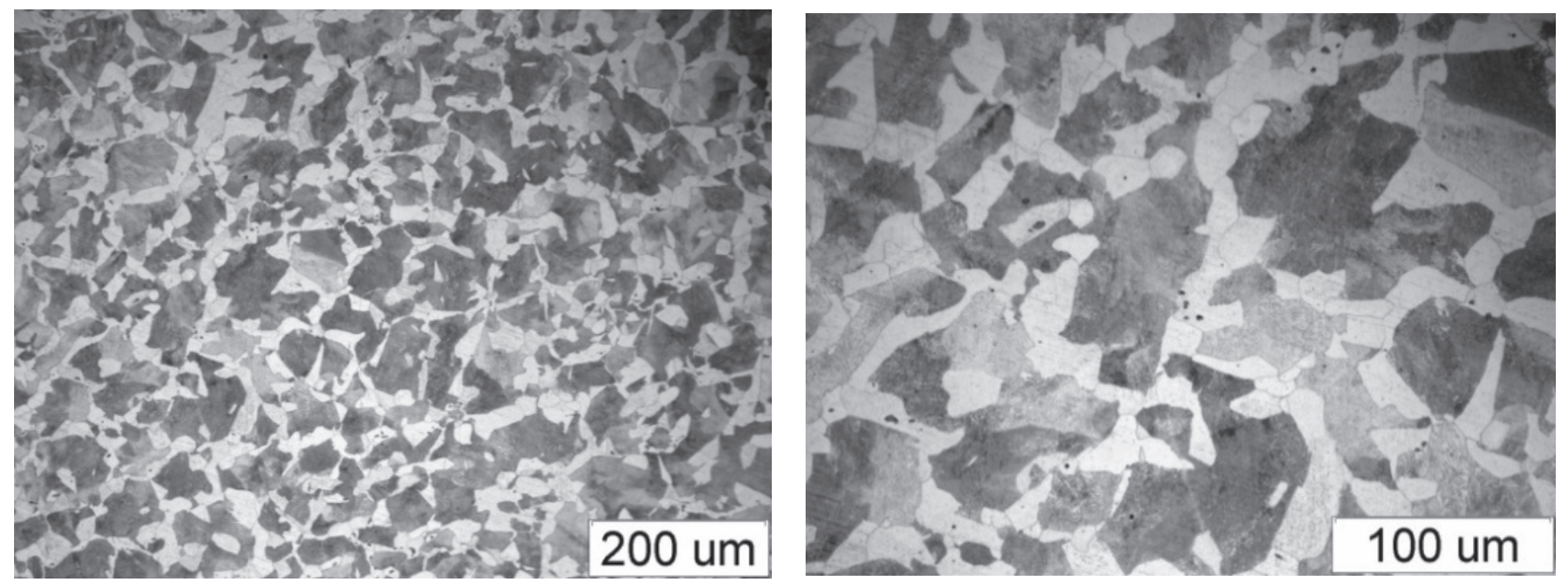


\section{Scanning microscope}
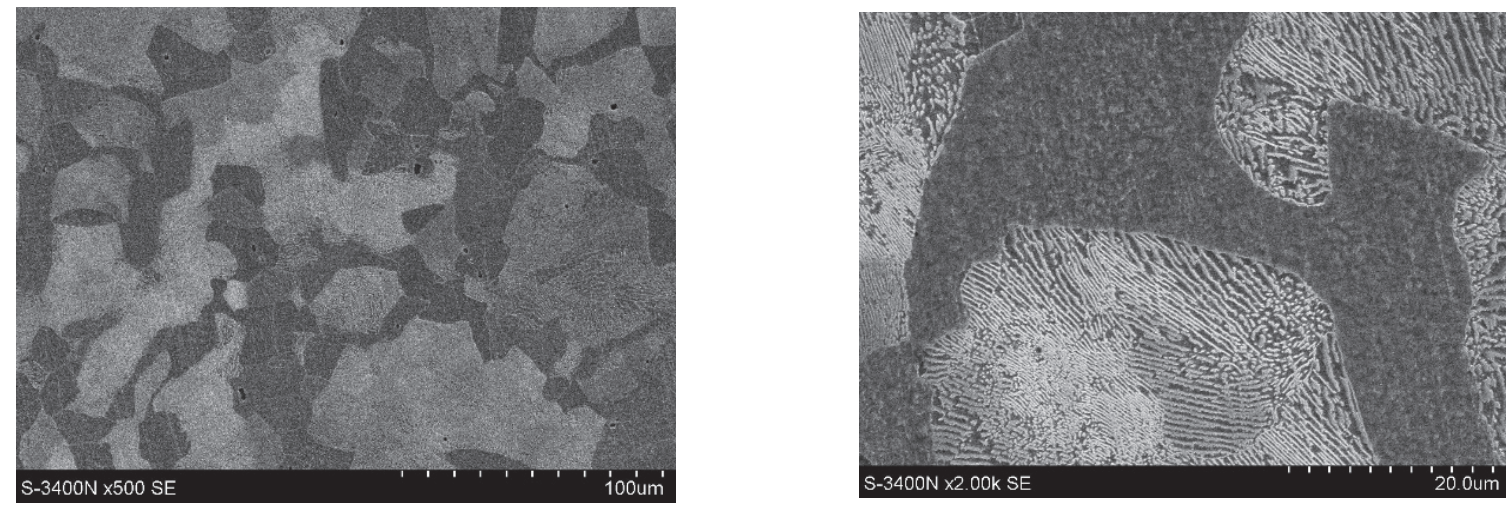

Figure 3 Examples of the microstructures of steel 42CrMo4S4 - $\phi 150 \mathrm{~mm}$ bar

Assessment of the primary grain size of austenite was performed according to the ASTM E112 scale. No correlation was found between the degree of processing and the grain size. All results fall within a narrow range of the grain size from 8 to 9 . The determination of the surface and linear fraction of structural components in the steel was carried out using the Met-llo application [3]. In the specimen taken from the $\$ 90 \mathrm{~mm}$ bar, the linear fraction of ferrite amounted to $15.2 \%$ and the linear and surface fraction of pearlite was $84.8 \%$. In the specimen taken from the $\$ 200 \mathrm{~mm}$ bar, the fraction of ferrite was smaller and amounted to $5.2 \%$, with a pearlite fraction of $94.8 \%$.

\section{MECHANICAL TESTS}

A static tensile test was carried out in accordance with standard PN-EN ISO 6892-1:2016 using the AMSLER 60ZD 1368 strength testing machine with a measurement range from 10 to $500 \mathrm{kN}$. Mechanical properties $\left(R_{m}, R_{0,2}, A_{5}\right.$ and $\left.Z\right)$, depending on the bar diameter and sampling location, are presented in Figure 4.
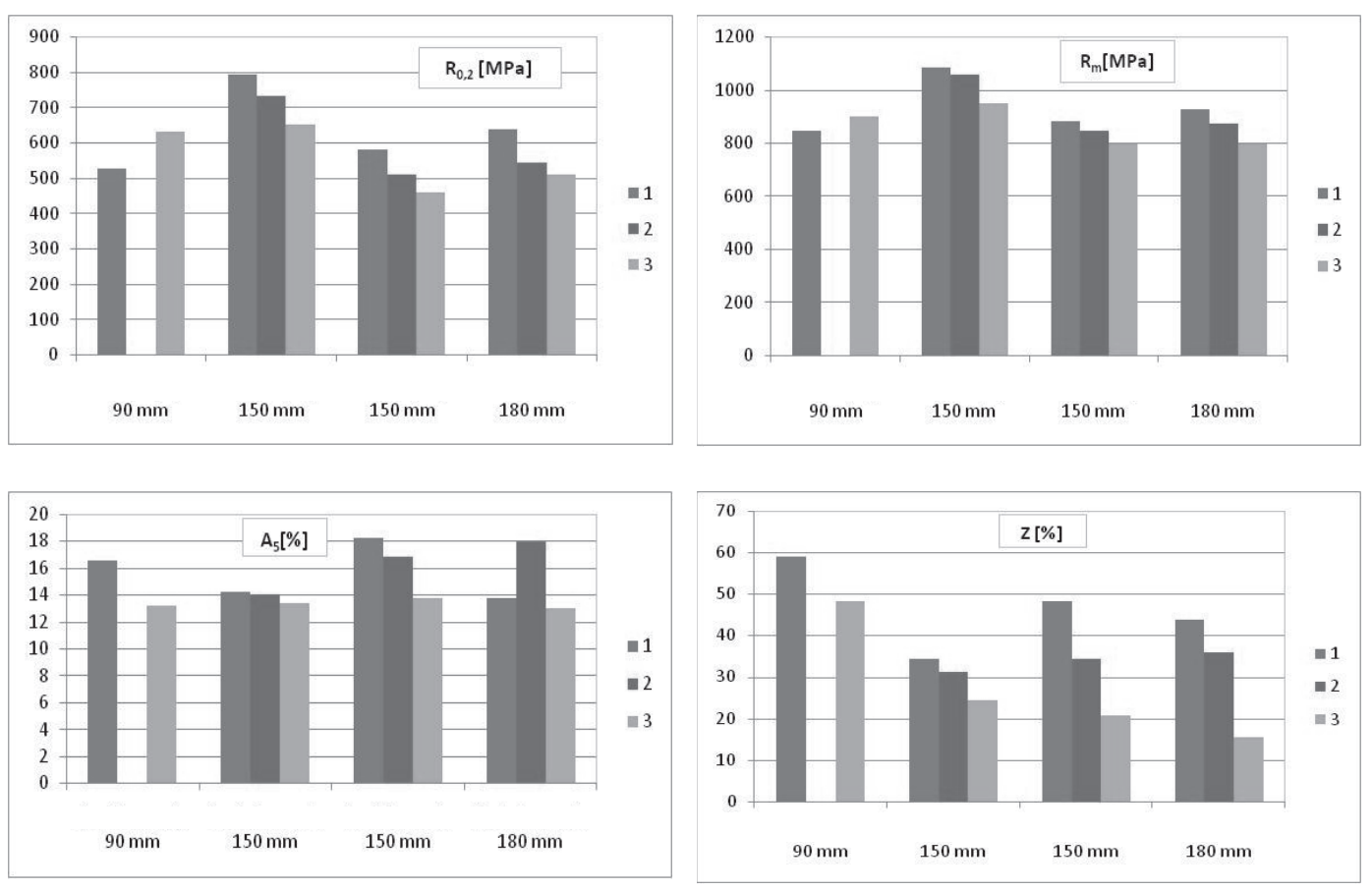

Figure 4 Collation of the results of mechanical properties tests for steel 42CrMo4S4:

a) yield stress, b) tensile strength, c) elongation, d) reduction of area 
The results of the tensile test show significant differences in strength properties, independent of the degree of plastic processing. Yield point $R_{p 0.2}$ changes from 516 to $726 \mathrm{MPa}$, and tensile strength $\mathrm{R}_{\mathrm{m}}$ changes from 869 to $1034 \mathrm{MPa}$, where the highest values refer to the $\phi 150 \mathrm{~mm}$ bar. Elongation $\mathrm{A}$ falls within the range from 13.9 to $16.3 \%$, and reduction of area $Z$ from 29.9 to $53.6 \%$, with the highest values for the $\phi 90 \mathrm{~mm}$ bar, for which the degree of plastic processing is the highest. Impact strength tests were performed on specimens with a $\mathrm{V}$ notch using a Charpy pendulum machine, Zwick/Roell RKP 450, in compliance with standard PN-EN ISO 1481:2017-02. Results of the impact tests, depending on the bar diameter, are presented in Figure 5. The highest impact strength $\mathrm{KV}$ of $38 \mathrm{~J}$ was obtained for the specimen taken from the $\phi 90 \mathrm{~mm}$ bar at a distance of $12.5 \mathrm{~mm}$ from the surface, while in the axis of the specimens, the impact strength is $14 \mathrm{~J}$ and is comparable to that of the specimens sampled from the other rods.

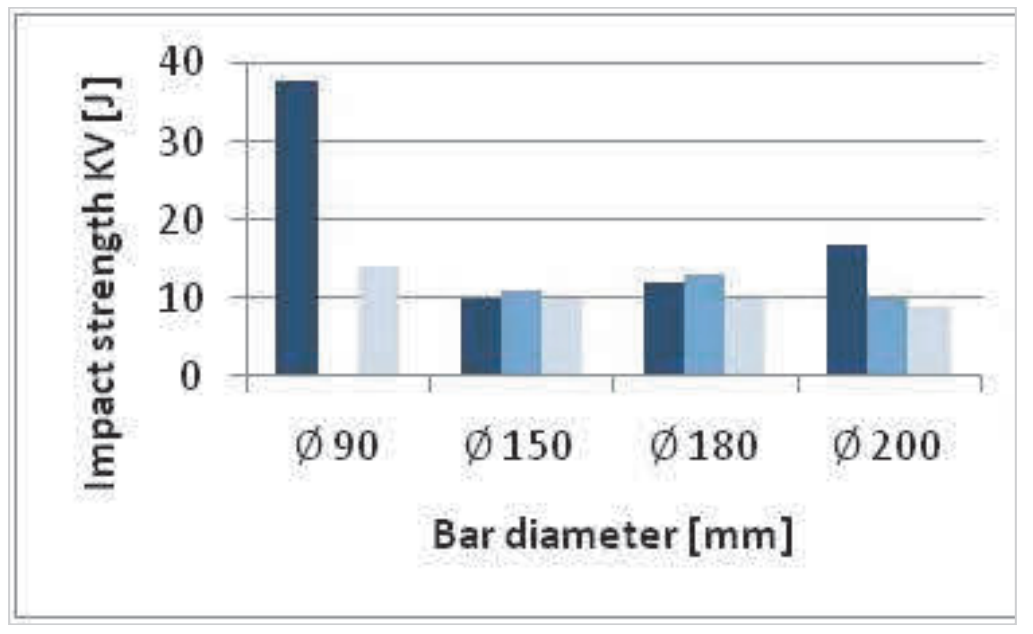

Figure 5 Impact strength $\mathrm{KV}$ of steel $42 \mathrm{CrMo} 4$ depending on the diameter of the rolled bar

$12.5 \mathrm{~mm}$ from the surfec, $\square 1 / 2$ radius, axis

Hardness of the steel was examined by means of the Brinell method, with a Rockwell-Brinell KP $15002 \mathrm{P}$ hardness tester, using a $5 \mathrm{~mm}$ steel ball at a load of $250 \mathrm{~kg}$. The hardness ranges from 208 to $248 \mathrm{HB}$, with the highest hardness value for the $\$ 150 \mathrm{~mm}$ bar, for which also the highest strength was demonstrated. Similarly to the impact test, the sampling location had a greater influence on the obtained results than the dimensions of the bar.

\section{CONCLUSIONS}

1) Visual examination of the discs cut out from rolled $42 \mathrm{CrMo} 4$ steel bars after Baumann's test revealed the presence of central porosity in the material, as well as a dendritic structure and numerous pinholes in the edge region.

2) It was found in the microstructure tests that steel $42 \mathrm{CrMo} 4$ had a pearlitic structure with the presence of a cementite lattice. Bars with a smaller cross-section had a homogeneous fine-grained structure. Large diameter bars were characterized by diverse cross-sectional structures, with the grain size increasing the closer to the bar axis.

3) No influence was found of the bar diameter on its mechanical properties. Both the results of tensile and impact strength tests, and hardness measurements indicate the significance of the place from which specimens are sampled. Significantly higher strength and hardness were obtained for the $\phi 150 \mathrm{~mm}$ bar in relation to $\phi 180$ and $\phi 200 \mathrm{~mm}$ bars, with a comparable degree of plastic processing. The quality of stock and rolling conditions should be considered to have an effect on the mechanical properties of the product. 


\section{ACKNOWLEDGEMENTS}

The research was carried out as part of the work NB-139/RM3/2017 entitled: Evaluation of technological and material parameters in hot rolling process of bars made of alloy steel types: determination of the influence of heating process of the batch on the type and quantity of scales, determination of phase transformations, structure and parameters of the hot rolling process and steel cooling, implemented as part of the development project no. POIR.01.01.02-00-0143 /16 entitled: Designed rolling of large size long bars with non-furnace treatment, implemented by Huta Bankowa Ltd. as part of the Intelligent Development Operational Program 2014-2020, Operation: $R$ \& D projects of enterprises, Sub-measure: $R \& D$ works related to the creation of a pilot / demonstration installation.

\section{REFERENCES}

[1] HERIAN, J. Rolling of long products, sheet metal and strips. Publishing House of the Silesian University of Technology, Gliwice 2014.

[2] SUŁKOWSKI, R. The influence of the degree of processing of a continuous S355J2 steel ingot on the structure and properties of hot rolled bars, Ph.D. Dissertation, Silesian University of Technology, Katowice 2009

[3] SZALA, J. Application of computer image analysis methods for a quantitative evaluation of material structure. The Silesian University of Technology Scientific Journals, "Hutnictwo" series z. 61, Gliwice 2001 